Sri Lanka J. Aquat. Sci. 11(2006): 75-83

\title{
A preliminary study on the presence of biofilms on food contact surfaces in selected Sri Lankan fish \& shrimp processing factories: setbacks in current cleaning process
}

\author{
M.G.I.U. KARIY A W ASAM*, AND S.P. JA Y ASOORIY A \\ National Aquatic Resources Research and Development Agency, Colombo \\ 15, Sri Lanka \\ *Corresponding author: E-mail: indunikariyawasam@yahoo.com
}

\begin{abstract}
Biofilms are a matrix of microorganisms which are adhered to and colonized a surface. When formed, they are very difficult to remove and act as a source of contamination in fish and shrimp processing environments. This study was undertaken to investigate the presence of biofilms, their bacterial composition on food contact surfaces in selected fish and shrimp processing factories as there are no records available on this aspect in Sri Lanka. Swabs were taken from selected food contact surfaces in two fish processing factories and two shrimp processing factories 6-8 $\mathrm{h}$ after the day's major cleaning operation. Biofilm formation was quantified by Aerobic Plate Count (APC) and Escherichia coli counts. Bacteria present on the biofilms were also identified to their generic or species level.

Surface adhered bacteria in surveyed fish processing plants had different levels of APCs [in Colony forming units (CFU)]: on deheading and lolling tables $10^{3} \mathrm{cfu} / \mathrm{cm}^{2}$; filleting boards $10^{3} \mathrm{cfu} / \mathrm{cm}^{2}$; trimming boards $10^{4}$ $\mathrm{cfu} / \mathrm{cm}^{2}$; knives $10^{6} \mathrm{cfu} / \mathrm{knife}$; gloves $10^{5} \mathrm{cfu} / \mathrm{glove}$; storage boxes (plastic) $10^{5} \mathrm{cfu} / \mathrm{cm}^{2}$; small cutting boards $10^{6} \mathrm{cfu} / \mathrm{cm}^{2}$; water buckets $10^{6} \mathrm{cfu} /$ bucket. E. coli were found only on some of the food contact surfaces viz. knives (5.0 cfu/knife); storage boxes and filleting boards $\left(<1 \mathrm{cfu} / \mathrm{cm}^{2}\right)$. Food contact surfaces in the shrimp processing plants had biofilm formation with high levels of APCs and different levels ofE. coli: on grading table, APC 8.9x10 $0^{4}$ $\mathrm{cfu} / \mathrm{cm}^{2}, E$. coli $<1 \mathrm{cfu} / \mathrm{cm}^{2}$; on processing table, APC $10^{7} \mathrm{cfu} / \mathrm{cm}^{2}, E$. coli $<1 \mathrm{cfu} / \mathrm{cm}^{2}$, on gloves APC $10^{7} \mathrm{cfu} / \mathrm{glove}$, E. coli $4 \mathrm{cfu} / \mathrm{glove}$; on block pan APC $10^{5} \mathrm{cfu} / \mathrm{cm}^{2}, E$. coli $2 \mathrm{cfu} / \mathrm{cm}^{2}$, on selecting boxes APC $10^{5} \mathrm{cfu} / \mathrm{cm}^{2}$, and on bowls used for washing shrimps APC $10 \mathrm{cfu} / \mathrm{bowl}$, E. coli 8 cfu/bowl. Predominant bacteria identified in all selected food contact surfaces in the fish processing plants wereBacillus circulans, Bacillus subtilis, other Bacillus sp., Micrococcus sp., Aerococcus sp., Flavobacterium sp., Pseudomonas fluoroscens, and Pseudomonas aeruginosa. Salmonella, E. coli, were found to occur at a lower frequency. In the shrimp processing food
\end{abstract}


contact surfaces, Alcaligenes, Micrococcus, Aeromonas hydrophila, Bacillus subtilis, Bacillus circulans, other Bacillus species, Flavobacterium, Pseudomonas species, Enterobacter aeroginosa, E.coli and Salmonella were also found nevertheless the incidence was low. This study showed that food contact surfaces in fish and shrimp processing industry supply an excellent environment for biofilm formation irrespective of the different cleaning methods used at present. Gloves, small cutting boards used on the top of the tables and knives are of high affinity to contaminate the product with its detached biofilm bacteria.

\section{Introduction}

In fish processing plants, microorganisms could attach themselves on to solid surfaces and form biofilms, in the presence of required nutrients, minerals, and organic matter. When these bacteria occur in a colony, they are found to be more resistant to sanitizers and antimicrobial cleaning agents than free-living bacteria. As a result it is difficult to remove or neutralize biofilms on food contact surfaces and equipment by normal cleaning and these microorganisms pose a safety hazard in the fish processing industry.

Scraping, swabbing, rinsing, microscopic beads, vortexing, agar flooding and direct agar contact (Rodac plates) can be used to study the biofilm formation and to obtain total viable counts to enumerate the biofim bacteria (Tebbutt. 1991). Some techniques of monitoring biofilm formation include the use of electronic microscope, NMR-technique, Fourier transformation infrared spectroscopy, quartz crystal microbalance and cellular automation (Tebbutt 1991).

The material of the surface has little or no effect on biofilm development. Stainless steel is just as susceptible as plastic pipe. Studies have shown that microbes will adhere to stainless steel, Teflon, PVC and PVDF (Kynar) and anywhere that has continuous contact with product is possible, especially where surface irregularities occur (Bagge 2001). Detection of biofilms can be difficult because they can enter a viable but non culturable state, meaning that they will not grow in media used to culture and detect their presence. In addition, swabbing is not always sufficient to remove the biofilm and the cells contained within it.

Prevention of biofilms is not necessarily easy but biofilms can take several days to stabilize. If certain guidelines are followed a problem should not develop. A serious problem for those in the fish processing business is biofilms which hosts bacteria known to attach to surfaces where they grow to form surface-associated communities. Spoilage organisms such as Pseudomonas are known to form biofilms, as well as pathogens such as Listeria and Salmonella (Hood \& Zotolla 1997). Once a biofilm becomes established on a surface, these bacteria can contaminate the product. Objective of the present study was to investigate the presence of biofilms on food contact surfaces on selected fish and shrimp processing 
factories in Sri Lanka and to isolate and to identify the dominant bacterial species found in the biofilms.

\section{Materials and Methods}

\section{Selection of food contact surfaces}

Two fish processing factories (F1 and F2) and two shrimp processing factories (S1 and S2) were selected for swab sampling for biofilms. Sampling for food contacted surfaces was conducted using standard methods recommended by United States Public Health Service (USPHS 2003) for factory ware. In the fish processing factories surface of head-off (deheading) and lolling tables, filleting boards, trimming boards, knife blades, gloves, blue boxes (plastic) used for storage, small cutting boards, water buckets (plastic) were used for sampling. In the shrimp processing factories, surfaces of grading and processing tables, gloves, block pan (metal), selecting boxes (plastic), washing bowls (plastic) were the selected food contact surfaces for biofilm detection. Sampling was carried out after 68 hours from the day's major cleaning at three weeks interval for a period of five months.

\section{Sampling and transportation}

Tubes containing $10 \mathrm{ml}$ of sterile tryptone broth was used to wet the swabs at sampling. Cotton swabs were removed from its sterile packaging and holding it from the stick, cotton swab head was moisten in tryptone broth and excess broth was removed into the bottle. Swab was rubbed thoroughly over an area of $20 \mathrm{~cm} \mathrm{x} 10 \mathrm{~cm}\left(200 \mathrm{~cm}^{2}\right)$ at two places where food comes into contact. Horizontal and vertical motion was used for swabbing the surfaces. Then each swab was returned into its respective tryptone tube and lid was closed before transporting. Samples were kept at $0-4^{0} \mathrm{C}$ using ice packs in potable coolers and brought to the laboratory for testing.

\section{Analysis of samples for bacteria}

Swab was thoroughly rinsed in the broth and excess moisture was removed by pressing the swab to the bottle walls. Swab without the broth was removed and the broth was mixed using a vortex mixture. Appropriate dilutions were made from the swabbing liquid. Samples were analysed for Aerobic Plate Count (APC) with reference to the drop method (Sri Lanka Standards 1991) and Plate Count Agar (PCA) plates were incubated at 30 $\pm 1.0{ }^{0} \mathrm{C}$ for $72 \pm 2$ hours. Bacterial colonies showing different colony characteristics on PCA were purified by restreaking and pure cultures were used for characterization. Enumeration of $E$. coli was carried out using Petri films (3M) according to manufacture instructions. One milliliter form each 
dilution was plated on to Petrifilm ${ }^{\mathrm{TM}} \mathrm{CC}$ plates. Petri plates were incubated at $37 \pm 1.0^{\circ} \mathrm{C}$ for $48 \pm 2$ hours and the E.coli colonies were identified by the blue colour of the colonies closely associated with entrapped gas.

\section{Results and Discussion}

The Table 1 and Fig. 1 show that high density of bacteria exist in all most all food contact surfaces sampled. Knives, water buckets and gloves used in the fish processing factories have a high potential for biofilm formation (Table 1) since these surfaces tend to maintain a bacterial count over 5 (cfu/area) of $\log$ APC values throughout the five months of sampling time. In the shrimp processing factories conditions available for biofilm formation was much higher than that of fish processing since it had relatively high APC Log values ( $>4 \log$ APC) in all samples items. Especially gloves and washing bowl used for shrimp processing had high bacterial populations (Fig. 1). The plastic boxes, that are used to select the raw prawns, do not have smooth uniform surfaces but have rough edges and perforations which are suitable for colony formation.

Table 1: Mean log Aerobic Plate Counts (APC) of selected food contact surfaces in two fish processing factories (F1 and F2)

\begin{tabular}{lcc}
\hline Type of Surface & \multicolumn{2}{c}{ Mean log APC values* } \\
\cline { 2 - 3 } & F1 & F2 \\
\hline Deheading/gilling table $\left(\mathrm{cfu} / \mathrm{cm}^{2}\right)$ & 2.68 & 3.4 \\
Lolling table $\left(\mathrm{cfu} / \mathrm{cm}^{2}\right)$ & 3.28 & - \\
Filleting board/table(cfu/cm²) & - & 3.6 \\
Trimming board/table(cfu/cm²) & 4.0 & 4.2 \\
Knife blade(cfu/knife) & 7.27 & 4.98 \\
Gloves(cfu/glove) & 5.34 & 5.9 \\
Small cutting board (cfu/cm $\left.{ }^{2}\right)$ & 5.96 & - \\
W ater bucket (cfu/basket) & 5.66 & - \\
Blue box (cfu/box) & - & 5.1 \\
\hline
\end{tabular}

*mean values of samples over a period of five months 
Table 2: Mean log Aerobic Plate Counts (APC) of selected food contact surfaces in two shrimp processing factories ( S1 and S2).

\begin{tabular}{llc}
\hline Type of Surface & \multicolumn{2}{c}{ Mean log APC values* } \\
\cline { 2 - 3 } & $\mathrm{S} 1$ & $\mathrm{~S} 2$ \\
\hline Processing table $\left(\mathrm{cfu} / \mathrm{cm}^{2}\right)$ & 4.8 & 4.7 \\
Grading table $\left(\mathrm{cfu} / \mathrm{cm}^{2}\right)$ & 5.4 & 5.4 \\
Gloves $(\mathrm{cfu} / \mathrm{glove})$ & 7.5 & 7.5 \\
Selecting Box $\left(\mathrm{cfu} / \mathrm{cm}^{2}\right)$ & 5.5 & 5.2 \\
Block Pan $\left(\mathrm{cfu} / \mathrm{cm}^{2}\right)$ & 5.3 & 5.0 \\
W ashing Bowl $\left(\mathrm{cfu}^{2} / \mathrm{cm}^{2}\right)$ & 7.26 & 7.5 \\
\hline
\end{tabular}

*mean values of samples over a period of five months

All the utensils used for fish and shrimp processing come in to direct contact with either the raw fish or raw shrimp during the process and they also have perforated areas with uneven surfaces which make them highly eligible for sessile bacterial colony formation. It was observed that during daily cleaning the food contact surfaces such as buckets, knives and boxes are not thoroughly scrubbed off to remove the bacterial films. They are only subjected to routine washing before and after processing, that removes only the upper detaching layer of the biofilms. According to Johnsonet al. (2000) biofilm is hydrophobic, it resists being washed away by water. This means that even a near boiling water rinse will not completely remove a biofilm from the surface.

Surface adhered bacteria in surveyed fish processing plants had different levels of E. coli were found only on some of the food contact surfaces as shown in Table 2.E. coli were isolated from samples of storage boxes and filleting boards but had a value of $<1 \mathrm{cfu} / \mathrm{cm}^{2}$. Study also showed that similar to fish contact surfaces, food contact surfaces in the shrimp processing plants had mean $E$. coli of $<1 \mathrm{cfu} / \mathrm{cm}^{2}$ on Grading tables and also $<1 \mathrm{cfu} / \mathrm{cm}^{2}$ on processing table. Salmonella species were found only in one sample of a knife used by fish processing factory F1. 
Table 2: Percentage occurrence ofEscherichia coli among biofilm bacteria on food contact surfaces in fish and shrimp processing plants.

\begin{tabular}{|c|c|c|c|c|}
\hline $\begin{array}{l}\text { Food contact surface } \\
\text { of all fish \& } \\
\text { processing factories }\end{array}$ & Mean E.coli count & $\begin{array}{l}\text { Number of samples } \\
\text { positive for E.coli } \\
\text { count }(>1 \text { cfu/item or } \\
\left.\mathrm{cm}^{2}\right)\end{array}$ & $\begin{array}{c}\text { Total number of samples } \\
\text { analyzed }\end{array}$ & $\begin{array}{l}\text { Percentage of E.coli } \\
\text { positive samples }\end{array}$ \\
\hline Knife & $5.0 \mathrm{cfu} / \mathrm{knife}$ & 4 & 10 & 40 \\
\hline Filleting Board & $<1.0 \mathrm{cfu} / \mathrm{cm}^{2}$ & 1 & 5 & 20 \\
\hline Small cutting board & $5.0 \mathrm{cfu} / \mathrm{cm}^{2}$ & 3 & 5 & 60 \\
\hline Gloves & $4.0 \mathrm{cfu} / \mathrm{glove}$ & 7 & 20 & 35 \\
\hline Block pan & $2.0 \mathrm{cfu} / \mathrm{cm}^{2}$ & 3 & 10 & 30 \\
\hline Washing bowl-shrimp & $8.0 \mathrm{cfu} /$ bowl & 4 & 10 & 40 \\
\hline
\end{tabular}


Bacillus circulans, Bacillus subtilis, other Bacillus sp. Micrococcus sp., Aerococcus sp, Flavobacterium sp, Pseudomonas fluoroscens, Pseudomonas aeruginosa, were isolated and identified from all selected food contact surfaces in the fish processing plants while Salmonella, and E. coli, were isolated and identified on some food contact surfaces but the frequency of occurrence of species of Salmonella was very low. In the shrimp processing factories, food contact surfaces Alcaligenes, Micrococcus, Aeromonas hydrophila, Bacillus subtilis, Bacillus circulans, other Bacillus species, Flavobacterium, Enterobacter aeroginosa, Pseudomonas species, Salmonella and E.coli were also found but the incidence was low.

Pseudomonas aeruginosa was among the identified predominant species in the fish processing factories while in shrimp factories bacteria of the genus Pseudomonas, which were not identified to species level, were found in abundance. This is an indication to that of biofilm formation in the surfaces. According to Edstrom (2003), Pseudomonas aeruginosa is a pioneer in formation of biofilms with its ability for slime formation and it has the ability to attaché even to stainless steel surfaces and electro polished surfaces within 30 seconds of exposure.

Research has shown that regulated post-rinse sanitizer concentrations which are currently used by the processing plants will have very, very limited efficacy on biofilm bacteria. Johnson et al, 2000 suggests is that a higher concentration be applied to these areas with high film formation (such as $1,000 \mathrm{ppm}$ quat for floors and drains) but don't rinse with potable water. Instead, rinse with the sanitizer at the prescribed concentration to displace the more concentrated chemical at the appropriate post-rinse level (brewers digest, 2000).

It is necessary to clean and sanitize the equipment properly especially those that in contact with the product for a long period of time, after each processing cycle to minimize the biofilm formation. During cleaning, $\mathrm{pH}$ and concentration of the solutions have to be controlled and monitored. The $\mathrm{pH}$ of the acid solution must be maintained below 2 and caustic solutions must be maintained above $12 \mathrm{pH}$ to hydrolyze the polysaccharide coating that protects the biofilm. Care needs however to be taken to ensure that pitting of the stainless steel does not occur. Especially for small scale processors who have little capital the most effective and least expensive of all biocides to kill not only free living bacteria but those in the biofilms is chlorine. High concentration of chlorine is required to kill biofilms than to kill free-floating bacteria. However it is corrosive on the stainless steel surfaces. Chlorine dioxide sanitizers have also proven to be effective against biofilms(Edstron, 2003).

Especially made cutting boards with smooth polished even surfaces must be used for processing of fish as normal house hold cutting boards, which have small hills on them that can collect minute flesh particles. Even the specific boards food processing should also be replaced at regular intervals as scratches and cuts on the boards' surface can promote formation of biofilms. 
Knives used should be properly cleaned not only at the middle of the blade but also near the handle. In most cases knives are dipped in a water boiler after cleaning until the next production. But it was observed that the temperature of water was not maintained at boiling or near boiling temperature. When the temperature of dipped water is low to mesophilic range rather than inhibiting the bacterial growth it promotes the growth of bacteria. Therefore care should be taken either to properly maintain the water boilers or to clean the knives after each cycle and allow it to dry.

\section{References}

Bagge D., M. Hjelm, C. Johansen, I. Hubern \& L. Gram 2001

Shewanella putrefaciens adhesion and biofilm formation on food processing surfaces Applied Environmental Microbiology. 2001 May; 67(5): 2319-2325.

USPHS Department of Health 2003

Health Regulations for Food Service Establishments. United States Public Health Services, State of V ermont Agency of Human services Department of Health, Division of health protection food \& lodging program, Burlington. $88 \mathrm{p}$.

Edstrom E. 2003.

Preventing Animal Dinking W ater Emergencies. Edstrom Industries Laboratory Animal Management Association(LAMA) 7500 Flying Cloud Dr. Suite 900 Eden Prairie, MN 55344

Hood S K. \& E A Zottola 1997.

Growth media and surface conditioning influence the adherence of Pseudomonas fragi, Salmonella typhimurium, and Listeria monocytogenes bacteria to stainless steel. Journal Food Protection.;60:1034-1037.

Johnson D and H. D. Swanson 2000.

A Look at Biofilms in the Brewery ,Brewers Digest, SeptemberOctober. BIRKO Corporation, 9152 Y osemite street, Henderson: 2325

Lewandowski, Z. \& P. Stoodley 1995.

Flow induced vibrations, drag force, and pressure drop in conduits covered with biofilm. International IAWQ Conference W orkshop on Biofilm Structure, Growth, and Dynamics. 30 Aug. to 1 Sept. Noordwijkerhout, The Netherlands.

Ravishankar S. 2002 
Microbial Biofilms on Food Contact Surfaces- Detection and Control. Food Safety Watch: National Centre for Food Safety and Technology. Illinois Institute of Technology, Summit-Argo. Fall, Volume 12, No. 3

Sousa O.V ., R.H.S.F. Viera, T.R. Patel E. Hofer Mesquita 2001.

Effects of chlorine on cells of Vibrio cholerae, Food Microbiology, June, vol 18, no. 3 pp355-359

Sri Lanka Standards 1991

Microbiological test methods 516:Part 1-General guidance for enumeration of microorganisms-aerobic plate count at $36 \pm{ }^{\mathrm{P} C}$. Bureau of Ceylon Standards, Colombo 3, Sri Lanka. 9p.

Tebbutt, G.M. 1991.

An assessment of cleaning and sampling methods for food-contact surfaces in premises preparing and selling high-risk foods. Journal of Epidemiology and Infection. 106:319-327.

Zook, D. 1992.

The Microcosmos Curriculum Guide to Exploring Microbial Space, Kendall Hunt Publishing Company, Dubuque, 431 p. 
